\title{
Critical Incident Technique applied in nursing and healthcare sciences
}

\author{
Bengt Fridlund $^{1 *}$, Maria Henricson ${ }^{1}$ and Jan Mårtensson ${ }^{1}$ \\ ${ }^{1}$ School of Health and Welfare, Jönköping University, Sweden
}

Received: December 1, 2016; Accepted: January 16, 2017; Published: January 23, 2017

*Corresponding author: Professor Bengt Fridlund, School of Health and Welfare, Jönköping University, POBox 1026, 55111 Jönköping, Sweden. Tel: 0046 361012 33; E-mail: bengt.fridlund@ju.se

\begin{abstract}
Purpose: The aim of this study was to elucidate the development and current status of the critical incident technique (CIT), with focus on its fundamental definitions, guidelines, and pros and cons when applied in nursing and healthcare sciences.

Method: A theoretical reasoning based on the original literature and with the support of updated literature relevant to the CIT was used.

Results: A critical incident is a retrospective story generating an activity, a behaviour which, due to its retrospective perspective, can only be deemed critical in hindsight. The incident is critical if there is a major human activity which is sufficient to allow conclusions and predictions. The story has a clear beginning and a clear end, and its impact needs to be clear with a significant outcome, either positively or negatively. The CIT-procedure, still guided in five steps, is relevant to be appliedin several healthcare disciplines. It has been developed to visualise the experience as well as the subsequent action of the story. CIT is a suitable qualitative method for nursing and healthcare since it is significantly participant-controlled, as data collection is based on the individual/patient perspective.
\end{abstract}

Conclusions: CIT has in its further development become an appropriate qualitative method, i.e., an effective clinical tool when the purpose is to identify and follow-up on individual/patient behavior in terms of descriptions as well as actions of care and treatment.

Keywords: Behavior, Critical incident technique, Healthcare, Nursing, Qualitative method

\section{Introduction}

The critical incident technique (CIT) is a qualitative method that is insufficiently described in the method books. The same is true of its use and establishment in nursing and health science studies, except for in Australia, the UK and the U.S. [1-3]. One reason for this may be that the analysis level is descriptive and does not intend to interpret and is therefore seen as superficial from a nursing and health analysis perspective [4]. CIT with a focus on studying human behavior is, however, a suitable method to learn in order to have a tool in clinical practice when the intent is to identify as well as follow-up on individuals' (patients, personnel, relatives) behaviors and handling of care and treatment [5-7]. Therefore, the aim of this study was to elucidate the development and current status of the CIT, with focus on its fundamental definitions, guidelines, and pros and cons when applied in nursing and healthcare sciences.

\section{Background}

Like all qualitative methods, CIT has an established history, which in this case goes back to World War II. The psychologist John Flanagan was the head of the military aviation psychology programmer and studied pilot behavior in connection with critical incidents that arose in aviation missions during training or battle against the enemy. An unacceptably large number of pilots failed in their missions, which is why his interest was partly directed at studying the pilots' experiences of critical incidents (descriptions) and partly at observing what steps they took to handle them (actions). Flanagan analyzed the critical incident after success or failure by "working backwards" - retrospectively, which means studying what has already happened afterwards - to thereby identify the specific behavior that led to a positive or negative result (outcome or consequence). In terms of data collection, it is a matter of supporting or getting the participant to remember and describe real incidents, and not how things could have been or turned out. In other words, it is about the participant's "real" and experienced world. There are accordingly two focuses behind CIT: the researcher intends to identify the participant's capacity based on his/her actions in the critical incident and to determine whether the consequence of the actions constitute a significant positive or negative - contribution $[8,9]$.

\section{Method}

A theoretical reasoning based on the original literature and with the support of updated literature relevant to the CIT was used in order to describe, explain, compare, reflect and implicate the development of CIT.

\section{Concepts and terminology development}

Flanagan established the concept of CIT, but over the years, several other terms have been used both in and outside of nursing, such as "Critical Incident Analysis", "Critical Incident Reflection", "Critical Incident Exercise" and "Significant Event Technique" $[3,10,11]$. There are probably many reasons why the terminology has changed over the years, but one crucial reason 
is the ambiguity as to whether CIT is a methodology or a method [11]. Methodology differs from method by being an analysis of the principles that apply to methods developed by a discipline. Accordingly, methodology refers - besides to a number of methods - to logical and philosophical assumptions that form the basis of a discipline, as well as a study's set of methods [11]. It appears as if not even Flanagan was clear about whether CIT was a methodology or a method in that he establishes the concepts of technique and procedure, and also in extensive detail describes how the data collection shall be done, but not at all so in terms of the data analysis.

During the years, several studies $[4,5,9,12]$ have therefore pointed out that the data collection procedure has followed CIT's guidelines, but the analysis procedure has not been undertaken according to a clearly indicated philosophical analysis procedure. However, the starting point of CIT is to understand the participant's subjective world - how the individual him or herself experiences his or her circumstances - and over the years, it has largely become rooted in the phenomenological research tradition and the methodology where the participant's experiences (and behaviors) are embedded in and deduced from their lived descriptions through critical incidents [5,11]. For the researcher, it is a matter of getting to know the participant to be able to study his/her "true data", so-called lived experience to "perform the scientific task". In this case it means to - based on critical incidents - explore and identify what the participant experiences and which behaviors (activities, actions or steps) he/ she takes to handle the phenomenon in question. With a 60 -year psychological behavioral origin, focused on identifying "what people do", CIT has over the years been used in a number of disciplines (besides psychology), such as economics, marketing, education and pedagogy. In the past 20 years, CIT has also become increasingly used in the healthcare disciplines of dental health, medicine and nursing $[2,10,13]$.

\section{Definition}

A critical incident is a retrospective event that generates an action, which, due to its retrospective perspective, can only be determined as critical afterwards. Further, the incident is critical when the subsequent action is sufficient in itself to allow conclusions and predictions made by the person carrying out the act [8]. Furthermore, the event needs to have a distinct beginning and a distinct end and the action's intent as well as its effect need to be clear with a tangible outcome, i.e., either with a positive or negative consequence. An incident is the same as a dilemma, episode, event, or situation in/from the participant's life and these terms are therefore often used synonymously [11]. Similarly, adjectives like 'crucial', 'revealing', 'significant', 'important' or 'obvious' are used or preferred over 'critical'. Accordingly, it is of significance that the adjective intends to express or give the incident 'that extra certain something' and specific details that distinguish it from the common or everyday incident that the participant does not remember in the same way $[6,7]$. A very important difference is also that the specific incident focuses on the participant's behavior, and not the participant's attitudes, emotions, perceptions or opinions $[2,4,5]$. In other words, the researcher intends to get a subjective description of a specific incident that the participant personally experienced, and handled, i.e., it triggered an action which had a significant impact on the final result, also implying a consequence. The participant is therefore encouraged to remember a critical incident - describe the scenario concisely and extensively, what actions were taken - describe the actions and identify the significance of the incident in its context, and ultimately describe the action's results and what tangible (positive or negative) consequences they led to [8]. It is also important to understand that a critical incident can have more than one significance and that a single significance can figure into several incidents.

\section{Guidelines}

Flanagan established guidelines for how CIT shall be used, consisting of five steps [8]:

1. Determine the overall objectives of the determined action: Flanagan points out that the key decision is determining the purpose of the study [8,9]; meaning what the researcher wants to find out. Moreover, the researcher needs to conduct a literature review to discover and establish what is already known about the behaviors intended for study (actions done by patients, personnel, relatives).

2. Work out the plans and specifications to gather critical incidents in the established actions: Flanagan says that this planning and specification is absolutely crucial to the study's trustworthiness [8]; it is a matter of considering the number of critical incidents, determining who renders them, how they shall be collected, and where and when it shall be done. The set-up or design is accordingly necessary to identify the "right" participants whose "reflection-in-action" is intended to be studied in the form of rendered behaviors [3]. The setup therefore encompasses inclusion and exclusion criteria of the participants' socio-demographic (age, gender, etc.) and situational (e.g., professional experience, illness experience, care experience) natures. It is also about identifying, determining and exemplifying what a critical event is, i.e., what it needs to comprise to determine what is intended to be studied [9]. This takes place most simply by defining and indicating a critical incident in a context other than what is intended to be studied, e.g., if the purpose is to look for critical incidents that get a person to begin to exercise after a heart attack, the "faked" example can be to search for critical incidents that get a person to stop smoking in connection with chronic obstructive pulmonary disease.

Data collection: Flanagan points out that CIT is flexible and enables several data collection methods such as observations, interviews and open questionnaires [8]. The development has also led to researchers increasingly using group interviews, e-mail and journals as data collection methods. To provide an adequate exchange in terms of content and quality, an individual interview is expected to take 15-20 minutes and a written 
e-mail document should comprise 3-5 A4 pages [5]. The data collection needs to generate at least 100 critical incidents, but 'reality' often generates around 300 incidents [4, 14]. If the phenomenon is "significantly delimited", Flanagan says that 50-100 critical incidents are enough [8]. Every participant is expected to render two to three, but it will usually be far more critical incidents, which is why the number of participants in studies in nursing and healthcare contexts often need to amount to around 20-30 people [4]. But it is important to point out that the scope is based on the number of critical incidents provided and not on the number of participants involved [6], and that there are studies both within and outside nursing and healthcare contexts that comprise several thousand participants $[10,11]$. In order for the critical incident to be as complete and whole as possible, four requirements need to be set and met [8]: 1) focus on one (or more: but one at a time) critical incident that had a specific and strong positive or negative effect on the result of the phenomenon in question; 2) describe the incident precisely, carefully and thoroughly; 3 ) describe what led up to the incident; 4) describe how the incident's action impeded or assisted a successful or unsuccessful conclusion of the phenomenon in question. The descriptions can be operationalised to a battery of nine questions; see Figure 1. Before the battery of questions is used in a 'real-life situation', it needs to be reviewed to confirm whether the participants understand the questions, as well as if the questions yield complete and meaningful responses that are possible to analyze according to CIT [14].

Data analysis: Flanagan provides no direct analysis procedure, but points out that a pre-understanding, i.e. the experience the researcher has and usually proceeds from "upon encountering the phenomenon", is an asset in the subjective process that the analysis work entails [8]. The method is distinctly inductive, i.e., an unbiased search is done in text or upon observation for the phenomenon without having assumed in advance that certain conditions exist (deductive method) [15]. The purpose of the study is accordingly suitable - rooted in a literature review - as the starting point, or so-called 'frame of reference', from which the participants' behaviors are sorted and categorized, which leads to a consequence of the action after a perceived data saturation has been obtained [2]. The

- Where did the critical incident happen?

- Can you give a detailed description of what happened?

- Why was the incident critical for you?

- What did you do in connection with the incident?

- What was your mindset during the incident?

- What were your thoughts during and after the incident?

- What were your feelings during and after the incident?

- What did you find was the most demanding aspect of the incident?

- What has this incident meant to you since?

Figure 1: Questions to ask the participants to get a description of a complete critical incident. analysis levels, i.e. the categorizations go from behavior quotes to subcategories, on to categories and finally to main areas.

There are a large number of behaviors and subcategories that are clearly rooted to the empirical data. They indicate a distinct direction with a positive or negative relationship to the phenomenon in question, while the categories and above all the main areas - usually two or three in number [4,9] - are abstract and relatively neutral in their content and in relation to the phenomenon in question. Over the years, and especially for studies in nursing, the analysis procedure has left the phenomenological research tradition and become substantially similar to a qualitative content analysis at a manifest level (a what-level) $[4,5,11]$. This means that the researcher, inductively and based on the purpose, searches for behaviors and from there establishes meaning-bearing units that - on a descriptive level - lead to subcategories, categories and main areas. Then, a few years into the 2000s, studies in nursing developed the analysis work to separate what the participants experienced (descriptions) and what steps they subsequently took (actions) [16-18]. This entailed two different data analyses with associated result descriptions even if the analyses were dependent on one another and was carried out at the same time [4].

Interpretation and reporting: Flanagan believes that the last step, i.e., the discussion part, is the step that is deemed to demand the most of the researcher [8]. In terms of methodological considerations, the study's limitations need to be presented, and in that CIT has been incorporated into the qualitative methods, the typical qualitative method criteria of credibility, dependability, confirmability and transferability have been introduced $[10,19,20]$. One such aspect of credibility is the retrospective data collection where the risk of forgetting 'what it was like' increases in pace with the age of the critical incident, which is why there is a risk of "tailoring the truth". At the same time, the critical incident is so specific that it has "made an impact" on the memory, which minimizes reconstructions after the incident [8]. A dependability aspect that is brought up is that the selection of participants is not sufficiently representative [8,14], but based on the tradition of qualitative methods - a strategic or purposeful selection that is as variation-rich as possible is sought- prevent this condition $[2,4,15]$. A confirmability aspect is researcher bias, which means that the researcher has not mastered pre-understanding and subjectivity. It is then of great importance that the analysis is done "under controlled conditions", such as discussing and reflecting on the developing result with the help of researcher colleagues through so-called inter-rater reliability $[10,14]$ to achieve a negotiating consensus [15,21]. A transferability aspect is how usable the results are in similar national and international contexts [15].

With regards to consideration of results, like the methodological aspects, it has a systematic setup in documentation [4, 20]. The systematized setup consists of five levels: describing, explaining, comparing, reflecting and ultimately implicating. With regard to the descriptive level, there are two writing alternatives: either a summarizing section where the most significant findings of the full results are described, or a description of the main find- 
ings of the respective main areas. The explanatory level means that the descriptive content is deepened with the researcher's "own elaborated ideas" with support from the literature review. This is making comparisons at the next level between the researcher's results and other studies, primarily from the literature review, regarding the results' advantages and disadvantages. The reflective level means abstracting the obtained results to a higher theoretical level against a frame of reference (besides the purpose) either based on the literature review or on suitable theoretical base(s). Coping, empowerment, health literacy and social support are suitable theories [21] since they concern the behaviors in question. The final level, the implicative, means that this discussion section is concluded with the presentation of clinical and/or research implications to show how the results can be used in practice, but also in theory.

\section{Pros and cons}

CIT focuses on real situations influenced by both intellectual and emotional causes that generate behaviors and actions bad or good - which clearly provides guidance on how such as nursing care and healthcare can be improved. Today, when recommendations and guidelines increasingly strive for the utilization of a patient or individual perspective [10], CIT is a particularly suitable method since it is so significantly participantdriven/controlled, i.e., the data collection takes place based on the participant's perspective. Moreover, the data analysis does not force data (or the participants) into any predetermined framework - apart from the purpose of course - but rather inductively seeks and thereby identifies rare and unusual phenomena (behaviors). CIT is also useful when the "causes" are not known, but the phenomenon exists. A major asset of CIT is also that it allows several data collection methods to be used together in a so-called 'method triangulation' to thereby identify the same phenomenon in different ways and from different perspectives $[5,10]$. It addition to this, the data collection usually provides rich information, is readily accessible and is inexpensive in financial and human resource terms [4, 9]. Another advantage is that CIT's deficiencies are pointed out and given, and that there are suggestions of how they shall be handled and minimized $[8,10]$. A disadvantage (or advantage) of CIT is that the critical incident must be clearly defined, i.e., that the participant (and researcher) are clear about what needs to be explored and reported [6, 8]. Just as tricky is the difficulty of remembering critical incidents fully and correctly since there is a danger that they fade and lose their strength and clarity over the years [5]. This means that there are "old" critical incidents that remain unreported, as well as those for which only the most extreme and uncommon are reported. Another uncertainty is that the participant does not want or do not choose to report a critical incident for personal reasons [4].

\section{Conclusions}

A critical incident is a retrospective story generating a behavior and is critical if there is a major activity sufficient to allow conclusions and predictions made by the person her/ himself. The story has a clear beginning and end with a significant outcome, whether positive or negative. CIT with focus on real situations influenced by both intellectual and emotional causes has become an appropriate qualitative method, i.e., an effective clinical tool when the purpose is to identify and follow-up on individual behavior in terms of descriptions as well as actions of care and treatment. CIT is also a suitable qualitative method to be used in nursing and healthcare since it is significantly participantcontrolled as data collection is based on the individual/patient perspective.

\section{References}

1. Redfern S, Norman I. Quality of nursing care perceived by patients and their nurses: an application of the critical incident technique. Part 2. J Clin Nurs. 1999,8(4):414-421.

2. Kemppainen JK. The critical incident technique and nursing care quality research. J Adv Nurs. 2000; 32(5):1264-1271.

3. Keatinge D. Versatility and flexibility: Attributes of the critical incident technique in nursing research. Nurs Health Sci. 2002; 4(1-2):33-39.

4. Fridlund B. The critical incident technique. In: Henricson $\mathrm{M}$, ed. scientific theory and method. From idea to examination in nursing. Lund: Studentlitteratur. 2012.

5. Sharoff L. Critical incident technique utilization in research on holistic nurses. Holist Nurs Pract. 2007; 21(5):254-262. doi: 10.1097/01. HNP.0000287989.40215.87

6. Sharoff L. Critique of the critical incident technique. J Res Nurs. 2008; 13[4]:301-309. DOI: 10.1177/ 1744987107081248

7. Schluter J, Seaton P, Chaboyer W. Critical incident technique: a user's guide for nurse researchers. J Adv Nurs. 2007; 61(1):107-114. doi: 10.1111/j.1365-2648.2007.04490.

8. Flanagan JF. The critical incident technique. Psych Bull. 1954; 51(4):327-358.

9. Andersson BE, Nilsson SG. Work and training analyses by using the critical incident technique. Stockholm: Akademiförlaget. 1970.

10. Butterfield LD, Borgen WA, Amundson NE, Maglio AST. Fifty years of the critical incident technique: 1954-2004 and beyond. Qual Res. 2005; 5(4):475-497.

11. Bradbury-Jones $C$, Tranter S. Inconsistent use of the critical incident technique in nursing research. J Adv Nurs. 2008; 64(4):399-407. doi: 10.1111/j.1365-2648.2008.04811

12. Brookfield S. Using critical incidents to explore assumptions. In: MezirowJ, ed. fostering critical reflections in adulthood: A guide to transformative and emancipatory learning. San Francisco: JosseyBass Inc. 1990

13. FitzGerald K, Seale NS, Kerins CA, McElvaney R. The critical incident technique: a useful tool for conducting qualitative research. J Dent Educ. 2008; 72(3):299-304

14. Urquhart C, Light A, Thomas R, Barker A, Yeoman A, Coopers J, et al. Critical incident technique and explicitation interviewing in studies of information behaviour. Libr Inform Sci Res. 2003; 25:63-88. doi. org/10.1016/S0740-8188(02)00166-4

15. Fridlund B, Hildingh $\mathrm{C}$, eds. Qualitative research methods in the service of health. Lund: Studentlitteratur. 2000.

16. Svensson A, Fridlund B. Experiences of and actions towards worries among ambulance nurses in their professional life: A critical incident study. Int Emerg Nurs. 2008; 16(1):35-42. doi: 10.1016/j. ienj.2007.10.002. 
17. Gustafsson M, Wennerholm S, Fridlund B. Worries and concerns experienced by nurse specialists during inter-hospital transports of critically ill patients: a critical incident study. Intensive Crit Care Nurs. 2010; 26(3):138-145. doi: 10.1016/j.iccn.2010.01.002.

18. Ekblad H, Rönning H, Fridlund B, Malm D. Patients' wellbeing: experience and actions in their preventing and handling of atrial fibrillation. Eur J Cardiovasc Nurs. 2013;12(2):132-139. doi: $10.1177 / 1474515112457132$.

19. Guba EG, Lincoln YS. Competing paradigms in qualitative research.
In: Denzin NK, Lincoln YS, eds. Handbook of qualitative research. California: Thousand Oaks. 1994.

20. Fridlund B. Writing a scientific manuscript: Some formal and informal proposals. Eur J Cardiovasc Nurs. 2006;5(3):185-187.

21. Sandelowski MBJ, ed. Handbook for synthesizing qualitative research. New York: Springer Publishing Company. 2007.

22. Bartey E, Lawson V. Using health psychology to help patients: theories of behaviour change. Br J Nurs. 2016; 25(16):924-927. doi: 10.12968/ bjon.2016. 